\title{
Spatially enabled bushfire recovery
}

Katie Elizabeth Potts, Rohan Mark Bennett, Abbas Rajabifard

The University of Melbourne

Melbourne, Victoria AUSTRALIA

Phone: +61-416-531-866

Fax: +61-3-9347-2916

Email: kpotts@pgrad.unimelb.edu.au

Abstract

Over the last decade growth in spatial information use for disaster management has been considerable. Maps and spatial data are now recognized as critical elements in each of the four phases of disaster management: mitigation, preparedness, response, and recovery. The use of spatial information to support the phases of mitigation, preparedness and response to bushfires is widely understood. Less attention, however, has been given to the role of spatial information in the recovery. Moreover, the application of the spatially enabled society concept to bushfire recovery has not been explored. This paper explores the role that spatial information plays and could play in the recovery phase of a bushfire disaster. The bushfires in Victoria, Australia that took place during February 2009 are used as the primary case study. It is found that: Spatial information for recovery requires a pre-existing infrastructure; Spatial capacity must be developed across agencies dealing with recovery; Spatially enabled address and parcel information are the key dataset required to support all recovery tasks; Spatial integration of bushfire datasets (spread and intensity) require linking with planning regimes, and Spatial information that is volunteered could be incorporated into recovery activities.

Keywords: disaster management, disaster recovery, spatial data infrastructure (SDI), bushfire. 


\section{Introduction}

Despite being a critical resource in the recovery phase of disaster management, spatial information management is often overlooked in scenarios such as disaster recovery: a shared understanding of where and how spatial information can assist is not evident amongst agencies involved with recovery. The utility of spatial information in tasks including infrastructure repair, or health restoration is not always obvious due to the diverse areas of expertise required for these tasks. Recent examples in both developed and developing countries provide evidence of this (Garnett and Moore 2010; Chandra and Acosta 2010; Ingram et al. 2006). In bushfires the value that spatial information can add to tasks in the mitigation, preparedness, and response phases of disaster management has been realized and documented (c.f. Ellis et al. 2004; Mansourian et al. 2004; Ansante et al. 2007), however the role of spatial information within the recovery phase has not extensively been dealt with. Consequently, the potential of spatial information in bushfire disaster recovery remains largely unrealized in many cases (Mills 2008a).

To this end this paper aims to understand the use and potential use of spatial information in the recovery phase of bushfire disaster management. Contemporary understandings of disaster management and spatial data infrastructures (SDIs) are provided first. The limited understanding of spatial information in bushfire disaster recovery is revealed. An outline of the methodology and selected case study is then provided. Results of the case study are provided under headings related to the major tasks in disaster recovery. The results are used in the development of a number of principles and discussion points that are intended to guide the design of systems for utilizing spatial information in the recovery phase of disasters. The conclusion outlines how the principles might be further tested and refined.

\section{Background}

Despite variations in the number and categories, contemporary literature generally organizes disaster management into a cycle of phases. McLoughlin (1985) provides a now well-recognized example using the linked terms: mitigation, preparedness, response and recovery. The mitigation phase relates to the evaluation of vulnerability and negative impacts and reduction of long term risk. Preparedness focuses on organizing response. The response phase relates to the activities immediately before, during, and directly after an event. Recovery is regarded as the reconstruction of communities after a disaster has occurred. Due to the nature of some disasters there can be a blurred line between response and recovery, with differing opinions of where response ends and recovery begins. As mentioned the recovery phase is the focus here, more specifically the initial (short term) phases of the recovery.

Smith and Wenger (2007) further articulated the recovery phase. It can be divided into four elements: the social environment, the built environment, the natural environment, and the 
economic environment. Smith and Wenger (2007) suggest these four environments are referred to as 'the four pillars of recovery' and are interlinked and interdependent. Until all environments are restored to their former state the recovery is not considered complete. The primary components of each environment are shown in Fig. 1:
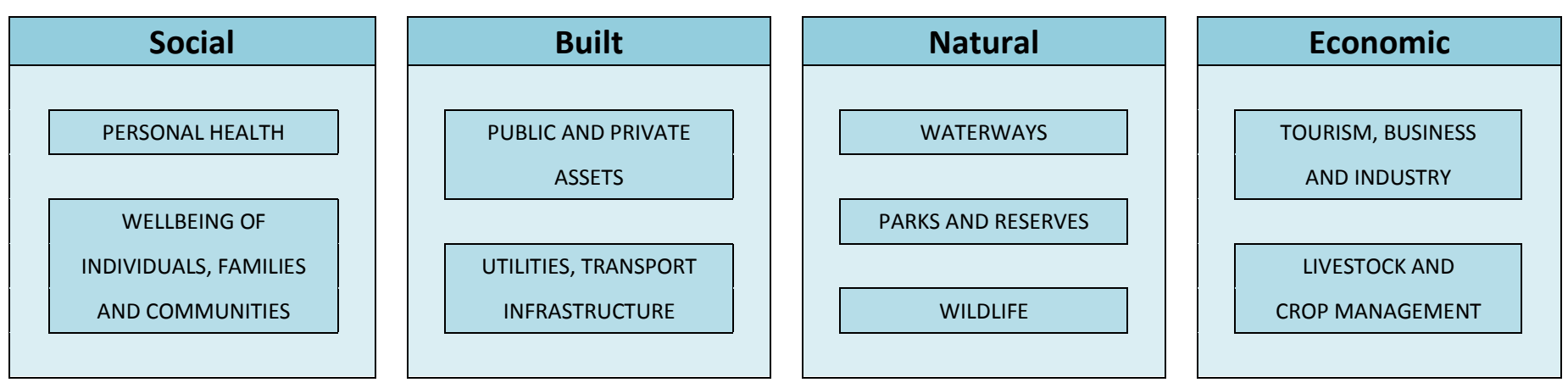

Fig. 1 The four pillars of disaster recovery (adopted from Smith and Wenger 2007)

Within these four environments the recovery process can be further broken down into seven tasks that focus on the urgent needs and recovery essentials of the communities affected by the disaster (ACT Government 2003). These tasks are:

1. Support for people affected by the event: the focus of this task is the immediate victims of the disaster and the communities affected. Providing medical support, health care facility admissions, injuries and patient transport, personal hardship grants, and counselling are all major activities associated with this task.

2. Ensuring public safety: this task is fulfilled by carrying out rapid impact assessments of the area to determine the extent of the damage.

3. Public information: this task is essential in disaster recovery; its focus is on informing and updating the public on the progress of the recovery. Petterson (1999) argues that when the public is kept informed of the recovery activities then success of the disaster recovery program is enhanced.

4. Restoration of essential services and infrastructure: the focus of this task is the restoration of power, water, gas, sewerage, telecommunications, roads and bridges to facilitate other recovery activities.

5. Clearance of land: the focus of this task is to safely remove all destroyed material from the parcels of land.

6. Environmental needs: this task focuses on the restoration of important environmental features that are assets to the community such as water catchments, ecosystems, landscapes and areas of significance.

7. Preparation for rebuilding: the primary focus of this task is the reconstruction of housing, businesses, and community facilities.

These frameworks provide a contemporary method of analyzing and understanding the nature and components of the recovery phase. 
Research by Mansourian et al. (2004) led to the development of models which identify factors required for using spatial information in disaster management; however the focus has been the response phase. Moreover, other recent research identifying a need for systematic and integrated use of spatial information for disaster management has focused on the preparedness and response phases (Asante et al. 2007). The recovery phase has received less attention (Mileti 1999).

In specific disasters such as Hurricane Katrina the use of spatial information in all phases has been documented (Mills 2008a; Curtis et al 2007). While the recovery phase is addressed in this particular case the focus is on hurricanes, the recovery phase in other disasters such as bushfires has not received attention. The lack of a defined role for spatial information in the recovery phase is noted by Mondschein (1999). Mills (2008a) proposes the implementation of a research agenda for disaster recovery and highlights that research into the roles of spatial information in disaster mitigation, preparedness and response has begun, however research into the role of spatial information in recovery is overdue.

In relation to the specific case of bushfire disaster management, the use of spatial information has been documented by a number of authors: Johnson (2000) identified GIS as a useful tool in disaster recovery and identified wildfire as a potential disaster where it could be utilized; Chou (1992) noted that the spatial technology of GIS has been used to assess the risk of wildfires in the United States of America during the phases of mitigation and preparedness; similarly the use of GIS to assess risk in a range of disasters has been documented by Atkinson et al $(2010 ; 2007)$. Further, Moodley et al (2006) reports the use of sensor web technology in the response phase of disasters. However, in all of these latter cases the primary focus was on the mitigation and preparedness phases of disaster management with the recovery phase being rarely addressed.

Recent natural disasters such as the Pakistan floods of 2010, earthquake in Haiti in 2010, Hurricane Katrina in 2005 and the Asian tsunami of 2004 emphasized the need for a systematic approach to the integration of spatial technology to support disaster management activities (Asante et al. 2007). Investigation of this idea found the concept of spatial data infrastructures (SDI) as an effective tool to facilitate this geospatial technology in a disaster management scenario (Mansourian et al. 2004).

SDI is an enabling platform to facilitate multi-sourced data access and integration (Mohammadi et al. 2010; Budhathoki et al. 2008). Fundamentally it is about coordinating the exchange and sharing of spatial data (Hjelmager et al. 2008). In recent years, SDIs have evolved from a theoretical framework to a legal and operational reality at many levels of organization (Molina and Bayarri, 2011). The advantages of the SDI framework over other networking solutions is that the SDI framework encompasses the policies, access networks, and standards, as well as the human resources necessary for the effective collection, management, and dissemination of the spatial data for a specific jurisdiction (Groot and McLaughlin 2000; Rajabifard et al. 2004; Masser 2005). In 
this way cultural, institutional, and business models receive equal research design attention to more technical components.

The use of SDIs as a tool for facilitating disaster management around the world is increasing due to the need for interaction between decision makers in the disaster management community and a need for better management and utilization of spatial data assets (Scholten et al. 2008; Mansourian et al. 2006; Rajabifard and Williamson 2004). The role fine-scale, people relevant data such as address and parcel layers is also becoming increasingly recognized (Williamson et al. 2010). So far success of SDI use in the response phase of the disaster management cycle has been reported; however the recovery phase has received less attention. Additionally, the emerging concept of spatial enablement (Rajabifard et al. 2010; Rajabifard 2007) and how it applies in the realm of bushfire recovery is yet to receive attention.

\section{Research Design}

In order to develop principles for incorporating spatial information into the recovery phase of bushfire disasters, an understanding of what information is used in bushfire recovery, how it is used, where the information comes from, and how spatial information could be better used was necessary. To achieve this, a qualitative research method utilizing an in depth case study was deemed appropriate (Yin 2003; Flick 2002; Denzin and Lincoln 2005; Yin 1993). The nature of this topic directed the design of case study towards exploratory: as already demonstrated, there are no well-defined models for the role of spatial information in bushfire recovery.

The 2009 Victorian bushfires acted as the case study event. The unprecedented scale of this recent bushfire disaster provided a rare opportunity to examine, define and refine the role of spatial information in the recovery phase. On February $7^{\text {th }} 2009$, 'Black Saturday', bushfires swept across the state of Victoria, Australia (Fig. 2). The fires impacted 80 communities, resulted in the loss of 173 lives, left hundreds injured, destroyed more than 2000 homes, and burnt over 3900 square kilometers of land and property. As a result of the injuries sustained in the fire 130 were admitted to hospital, 20 of them with serious burns (VBBRA 2009; Cameron et al. 2009). 


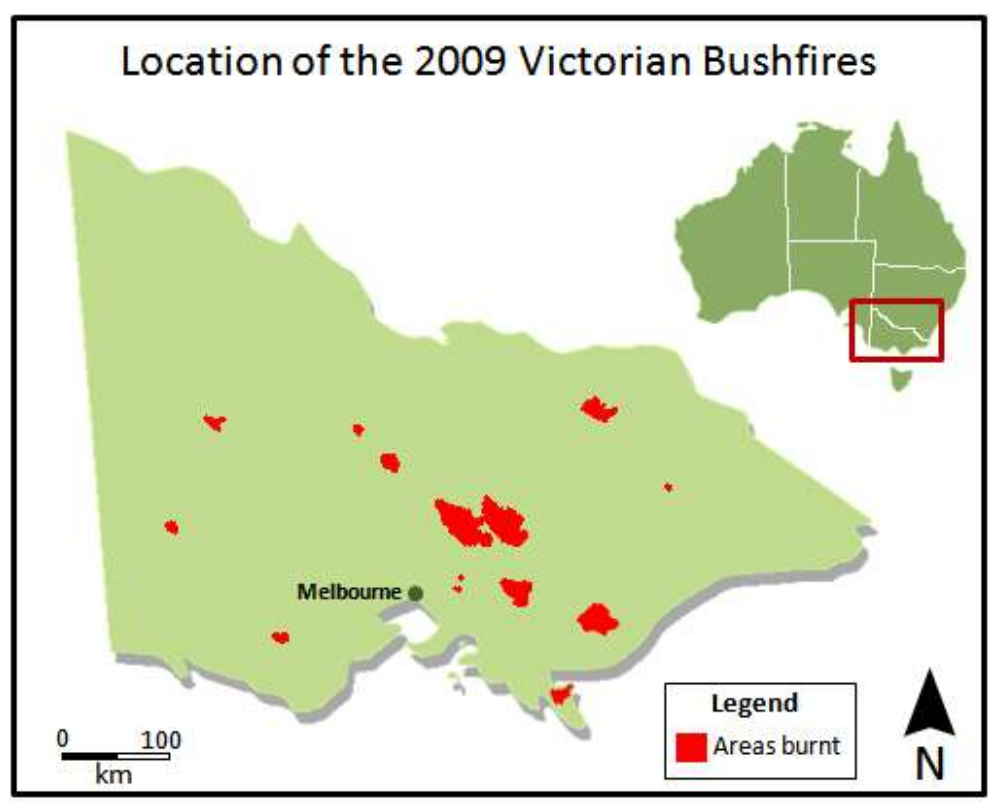

Fig. 2 Location of the 2009 Victorian Bushfires

In response to this disaster government at federal, state, and local levels, public organizations and private organizations formed a recovery effort. It was the biggest rebuilding and recovery activity in the state of Victoria's history. The Victorian Bushfire Reconstruction and Recovery Authority (VBBRA) was established by the Premier of Victoria on February $10^{\text {th }}$ to coordinate the recovery. As part of the recovery program organizations within the spatial information sector were called upon to contribute their skills, resources, and expertise. These spatial professionals and organizations came from backgrounds ranging from surveying to geographic information systems (GIS). The professionals were sourced from government departments, private organizations and volunteer groups.

The research underpinning this paper required an understanding of who created, managed or used spatial information in the recovery phase. To obtain this information targeted studies of organizations involved with VBBRA were undertaken. The specific task involved covering a sample of all the users and creators of spatial information in all parts of the recovery phase; social, built, natural and economic. The studies were structured around the collection, storing, presentation and utilization aspects of spatial data. Spatial data clearinghouses, and in particular, disaster related clearinghouses were examined as a suitable option for managing this type of recovery operation. Spatial data clearinghouses facilitate access to required spatial data and improve the sharing and exchange of spatial data between suppliers and users (Crompvoets et al. 2004). While it has been recognised as an efficient method for data organisation and dissemination in disaster events, wide employment of the concept has not taken place (Mills et al. 2008b). This is despite the demonstrated value for all phases (mitigation, preparedness, response, recovery) of disaster management (Curtis et al. 2006; Mills et al. 2008b).

It should be noted that in the days following the disaster a royal inquiry was announced. The aim was to investigate the occurrences on the day, to gain an understanding of the disaster and how the 
risk of a similar tragedy occurring in the future could be minimized. The report of the inquiry was published subsequent to the completion of this study. The findings and their implications on this research are incorporated into the discussions that follow.

\section{Results}

Results are discussed in terms of seven tasks that were identified as the key aspects of the recovery. These seven tasks are developed from recovery operations undertaken in the past as a result of Australian bushfires that have devastated communities and caused the loss of life. In this specific case - the 2009 Victorian bushfires, the prompt completion of these tasks was critical due to over 7000 people being displaced and left homeless as a result of the disaster (Hodgkinson 2009). The inclusion of spatial information as a resource for these tasks provided valuable support during the recovery effort.

\section{Spatial information within the recovery}

The diversity of the recovery tasks, ranging from health to environmental meant that many different datasets and types of spatial information were required. These datasets were sourced from various Victorian government agencies such as the Department of Sustainability and Environment (DSE), the Department of Human Services (DHS), the Department of Primary Industries (DPI), the Victorian Electoral Commission (VEC), the Office of Emergency Services Commissioner (OESC), the Country Fire Authority (CFA), from the private sector - AAMHatch, and from the satellites Landsat and SPOT. A summary and description of the spatial information utilized in the recovery phase of the disaster and the tasks associated with each dataset are shown in Table 1. In brackets are the custodian agencies of the specific spatial data sets.

Table 1 A summary of the spatial information available during the recovery

\begin{tabular}{|c|c|c|c|c|c|c|c|c|}
\hline Name of spatial data & $\begin{array}{c}\text { Task } \\
1\end{array}$ & $\begin{array}{c}\text { Task } \\
2\end{array}$ & $\begin{array}{c}\text { Task } \\
3\end{array}$ & $\begin{array}{c}\text { Task } \\
4\end{array}$ & $\begin{array}{c}\text { Task } \\
5\end{array}$ & $\begin{array}{c}\text { Task } \\
6\end{array}$ & $\begin{array}{c}\text { Task } \\
7\end{array}$ & Description \\
\hline Vicmap Addresses (DSE) & $\mathbf{X}$ & $\mathbf{X}$ & & & $\mathbf{X}$ & & $\mathbf{X}$ & $\begin{array}{l}\text { Current database of address points } \\
\text { across Victoria }\end{array}$ \\
\hline Vicmap Property (DSE) & & $\mathbf{X}$ & & & $\mathbf{X}$ & & $\mathbf{X}$ & $\begin{array}{l}\text { Line and polygon features delineating } \\
\text { key administrative boundaries across } \\
\text { Victoria }\end{array}$ \\
\hline $\begin{array}{l}\text { Vicmap Vegetation } \\
\text { (DSE) }\end{array}$ & & & & & & $\mathbf{X}$ & & Vegetation coverage across Victoria \\
\hline Vicmap Hydro (DSE) & & & & & & $\mathbf{X}$ & & $\begin{array}{l}\text { Natural and man-made hydrographic } \\
\text { features across Victoria }\end{array}$ \\
\hline Vicmap Transport (DSE) & & & & $\mathbf{X}$ & & & & Transport network across Victoria \\
\hline $\begin{array}{l}\text { Aerial photography } \\
\text { (Victoria Police) }\end{array}$ & & $\mathbf{X}$ & & & $\mathbf{X}$ & & & Aerial images taken post disaster \\
\hline Imagery (AAMHatch) & & & $\mathbf{X}$ & & & & & $\begin{array}{l}\text { Car based video data taken post } \\
\text { disaster }\end{array}$ \\
\hline
\end{tabular}




\begin{tabular}{|c|c|c|c|c|c|c|c|c|}
\hline $\begin{array}{l}\text { Satellite imagery } \\
\text { (Landsat, SPOT) }\end{array}$ & & & $\mathbf{X}$ & $\mathbf{X}$ & & $\mathbf{X}$ & & $\begin{array}{l}\text { Satellite images taken during and post } \\
\text { disaster }\end{array}$ \\
\hline Fire extents (CFA) & & & $\mathbf{X}$ & & $\mathbf{X}$ & $\mathbf{X}$ & & Boundaries of the fire affected areas \\
\hline DHS Asset layers (DHS) & $\mathbf{X}$ & & & & & & $\mathbf{X}$ & $\begin{array}{l}\text { Point based data indicating the } \\
\text { location of the department of human } \\
\text { services owned assets (hospitals, aged } \\
\text { care etc) }\end{array}$ \\
\hline $\begin{array}{l}\text { Victorian Electoral Roll } \\
\text { (VEC) }\end{array}$ & $\mathbf{X}$ & & & & & & & $\begin{array}{l}\text { Database containing personal details } \\
\text { including the names and registered } \\
\text { addresses of the Victorians }\end{array}$ \\
\hline $\begin{array}{l}\text { Rapid Impact } \\
\text { Assessment Data (DPI) }\end{array}$ & & $\mathbf{X}$ & $\mathbf{X}$ & & $\mathbf{X}$ & & $\mathbf{X}$ & $\begin{array}{l}\text { Primary industry information } \\
\text { collected during post disaster } \\
\text { assessments }\end{array}$ \\
\hline $\begin{array}{l}\text { Rapid Impact } \\
\text { Assessment Data (OESC) }\end{array}$ & & $\mathbf{X}$ & $\mathbf{X}$ & & & & & $\begin{array}{l}\text { Information collected during post } \\
\text { disaster assessments }\end{array}$ \\
\hline Established survey marks & & & & $\mathbf{X}$ & & & $\mathbf{X}$ & $\begin{array}{l}\text { Surviving survey marks that were } \\
\text { located post disaster }\end{array}$ \\
\hline
\end{tabular}

As can be seen directly from the table address and parcel information was most heavily utilized, and all of the seven tasks made use of spatial information. Fig. 3 shows a simplified representation of the information used in the recovery based on the findings from Table 1. The types of information were grouped into the categories: parcels and address information; natural resources information; and imagery. The final category of VGI was included to reflect the possible inclusion of this resource and which tasks would have utilized this type of information had it been available.

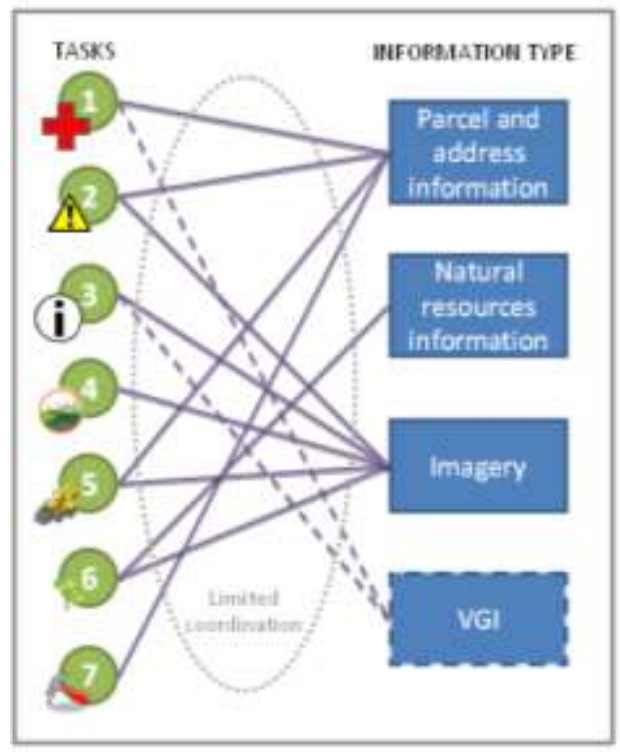

Fig. 3 Current use of spatial information in the 2009 bushfire recovery

\section{Task 1: Support for people affected by the bushfires}

The spatial information utilized during this initial task was firstly the Vicmap addresses dataset and the Victorian electoral roll, which were both used to identify and verify the location of 
residences. Secondly the GIS layer from the Department of Human Services was used to locate the government healthcare assets in the area to coordinate the allocation and treatment of patients. Key problems here related to the accuracy of the Vicmap address dataset and discrepancies between this dataset and the electoral roll delayed this process. The Vicmap address dataset contained all of the official names of each address, and when compared with the electoral roll addresses significant differences in the names of streets and house numbers were found. This is due to people registering another name or number as their address in the electoral roll. This caused delays because in order to verify a person and their address, the multiple names and numbers of the same streets had to be sourced and checked.

\section{Task 2: Ensuring public safety}

Due to the severity of the case study bushfire the task of ensuring public safety was divided into 3 stages;

1. Searches of every property for human remains

2. Rapid impact assessments

3. Marking of each property as safe for clearing

The severity of the bushfire was such that the number of fatalities was unknown. The estimated number of deaths immediately after the event was between 150 and 200. A large number of people were missing and unaccounted for. For these reasons a coronial order dictating that a search of every property in the affected area was required. As a result of this order only authorized people were permitted inside the disaster area during the search period. Involved in assisting the Coroner's Office with this task were the Victoria Police and the Victorian Institute of Forensic Medicine.

This enormity of this task and the pressure from the public and victims for conclusions meant that any information that could assist in accelerating the process was required. The Vicmap property and address spatial layers were offered and used to identify and locate all of the parcels in the affected area. The datasets were loaded into personal digital assistant (PDA) devices that contained a GPS and the locations that were visited during the search were recorded on the system to document the properties and locations that had been inspected. Additionally a geo-referenced camera was used to collect images from the site visits.

The second stage of this task involved conducting a rapid impact assessment on all of the properties in the affected area. This was to document the extent of the devastation caused to premises, livestock, and infrastructure, and to determine the existence of any dangerous material. These assessments were conducted on behalf of the Office of the Emergency Services Commissioner (OESC) by Victoria Police and the Australian Defence Force (ADF). 
The information for the assessment was collected on paper forms that requested details such as: the property address, a map grid reference, the latitude and longitude, the affected persons details, the state of the premises (accessible/destroyed/habitable), details of the damage, injuries of any livestock, and details of damaged infrastructure. The intention was for this information to be input into a computer after collection to allow for a GIS layer to be created from it. This would then allow for the location of each property that had been assessed to be matched with the current Vicmap address and property layers to verify the information. This plan was unsuccessful however due to a number of factors: firstly, the quality of the information gained from the RIA form was not of a standard required to create an effective GIS layer. The reason for this was determined to be the spatial understanding of the collectors of the information. They were not aware of the requirements or details needed to create a GIS layer, and were unable to record the information in a useful way. Further, the nature of the disaster meant that most of the information requested on the form did not exist. Street signs, house numbers and other forms of property identification were destroyed. Secondly, the GIS layer did not eventuate as planned due to logistical reasons. The inputting of the information from paper to computer was incredibly time consuming and labor intensive. As a result, of all the information input into the computer, only $20 \%$ of the data was available and of a standard to enable the creation of a GIS layer.

The function of this stage was to complete the task of ensuring public safety by removing any dangerous materials or hazards that were identified as a result of the rapid impact assessments or coronial investigation.

\section{Task 3: Public Information}

A key communication tool that was available for victims and people directly affected by the fires was a database with a web interface that facilitated the lodgment of insurance claims, identification and verification of property locations and property details. This system was set up by a private spatial information firm and hosted data such as the authoritative Vicmap data which contained the address, property and many other datasets. The purpose of this database was to allow for the sharing and management of spatial data between organizations involved in the recovery. The use of licenses enabled the information to be restricted so that only authorized persons were able to view the data. This system was mostly effective, however due to the urgency in which it was set up after the disaster data integration and data duplication issues arose. A further issue that occurred was data inaccuracy, which was due to the varying quality of data received from different government departments. As a consequence of this data inaccuracy property identification was made much more difficult. To rectify these problems owners needed to log onto the database to correct the location of their address. 


\section{Task 4: Restoration of essential services and infrastructure}

Key spatial data utilized in this recovery task was the Vicmap transport dataset, aerial imagery (pre and post disaster), and GIS asset layers detailing the infrastructure. The organizations involved in this task were familiar with the spatial data required and as a result problems regarding spatial inaccuracy or duplication of data were not reported.

\section{Task 5: Clearance of parcels}

In order for this task to efficiently take place verification of property addresses and property boundaries was necessary. The extent of damage the bushfire caused resulted in properties becoming unidentifiable and boundaries such as fences no longer existing. Re-establishment of these boundaries was required. This was a large project sub-managed by the Office of the Surveyor General in Land Victoria (Department of Sustainability and Environment). The private sector was heavily involved. Initially, existing survey marks and monuments located in the area were used, however many were destroyed in the fire and needed to be replaced (Cichocki 2010). A further difficulty arose in this task due to the limited telecommunication coverage which restricted GPS updates for RTK (real time kinematic). Other spatial information used in this task was the Vicmap property and addresses datasets, the CFA fire extent data, and the aerial imagery provided by the Victoria Police.

\section{Task 6: Addressing critical environmental needs}

During this task the spatial datasets displaying the vegetation and hydrology of the area affected by the event (Vicmap vegetation and Vicmap hydro), satellite imagery captured post disaster, and the CFA fire extents were made use of. These spatial datasets enabled a comparison of before event conditions to be compared to post event conditions which allowed an assessment of the damage resulting from the event to be assessed, as well as identification of any assets that were destroyed.

\section{Task 7: Major rebuilding preparations}

All of the previous tasks contribute towards this final task. Clearly understanding where each property is located and the address of that property is critical before any rebuilding takes place. GNSS master base stations were established in the areas by surveyors to assist in this identification, and the Vicmap property and addresses datasets were also utilized. The problem associated with the inaccuracy of the address dataset was experienced in earlier tasks and was overcome before the commencement of this task. This meant that the finalization and verification of the addresses and boundaries could occur, permitting rebuilding to begin. 


\section{Discussion: spatially enabling disaster recovery}

Many studies which provide invaluable understanding on the complexities, politics, and processes of disaster recovery have been carried out for a range of disasters in recent years (Chang 2010; Garnett and Moore 2010; Mills 2008a; Green et al.2007; Davis 2006). The application of these findings to a rapid impact bushfire (such as the Victorian bushfires) however has not been described in depth. The Victorian bushfires and its aftermath provided many lessons in relation to disaster management, particularly the recovery phase of bushfire disaster management. Based on this research a number of key principles and discussion points are now identifiable. Some of the discussions here make use of the royal inquiry findings completed in 2010. The inquiry was announced to investigate the bushfires, to gain an understanding on the disaster and how the risk of a similar tragedy occurring in the future could be minimized. Resulting from this inquiry was some 67 recommendations.

\section{Principle 1: Spatial information for recovery requires a pre-existing infrastructure}

While many of the tools involved with the recovery (e.g. RIA, online GIS) were well established, their utilization in the specific case of the bushfire was ad hoc. Moreover, a large amount of data duplication occurred when a range of organizations who previously had limited links, were required to collaborate. Information and system sharing was necessary. However, establishing effective collaboration usually requires a long-term approach. For this reason a number of the tools, such as the online GIS and RIAs, were ineffective, misunderstood and poorly utilized. In contrast, the approach for reestablishment of survey marks could make use of well defined procedures for undertaking these tasks. The professional skills, public-private collaborative approach, and spatial understandings were already in place and agreed upon. An argument for a pre-existing, potentially legislated approach for an agreed set of standards for state-based spatial information could be made here. Indeed, an example of this requirement was outlined in the commission's report. Specifically, recommendations 37 and 16 declare:

- that the state identify a central point of responsibility for and expertise in mapping bushfire risk

- that the DSE provide mapping data free of charge to emergency services

This is potentially the beginnings of a formalized approach to organizing spatial information in all aspects of bushfire disaster management, including the recovery phase. Fig. 4 provides a conceptualization of the pre-existing platform required. 


\section{Principle 2: Spatial capacity must be developed across government agencies}

A number of problems emerged due to limited spatial capacity of individuals and across agencies. The key issue here related to the circumstances created by the coroner: professionals with spatial expertise could not get access to key areas requiring their skill base. Collection, manipulation and management of spatial information needs to become a primary skill set for any individual or agency dealing with disaster recovery (Fig. 4). Again, recommendation 37 of the inquiry report supports this view, albeit organized through central coordination body.

\section{Principle 3: Spatially enabled address and parcel information holds the key}

Data relating to parcels and address are fundamental to the disaster recovery process (Fig. 4). These datasets are large scale and people relevant: they are understood by lay people and professionals on the ground. Unfortunately, inaccuracy and inconsistencies in address datasets are an ongoing problem. These datasets have developed from the community-up over long periods. In many cases, they are not legal definitions. Different agencies routinely use different address strings for the same property. In many cases, the addresses being used by those involved with recovery did not match what was used by local communities. This impeded many of the recovery activities. Vicmap Address, provided through DSE, is one of the best-maintained address datasets across any jurisdiction in Australia, however, work is still required to make it complete, authoritative, and erudite in the context of disaster and emergency management. A formalized and well funded regime of maintenance will be required to achieve this.

Another issue here relates to geocoding of addresses. In Vicmap Property each property gets a single geocode, however, the location of this geocode is not standardized. After a severe bushfire incident all physical house numbers, survey marks, and fences might be destroyed. Old aerial photography may no longer be relevant for use. Geocodes in datasets placed in ad hoc positions (e.g. front of parcel, corner of parcel) can become meaningless and create confusion (Ratcliffe 2001; Bonner 2003; Cayo and Talbot 2003; Ward et al. 2005). A standardized method for locating a parcel geocode appears necessary (Zandbergen 2008).

\section{Principle 4: Spatial integration of bushfire datasets (spread and intensity) require linking with land administration functions}

The rich sources of data produced during and immediately after the bushfires could be used more widely. Primarily they were used for the first 6 tasks of recovery; however, the rebuilding task arguably could make the most use of the datasets. For instance, planning for the rebuilding of communities should take into account the nature, spread, and institutes of the fires in various 
places. This will result in better recovery outcomes (due to possible changes to building regulations and government policies on land management) and also feed into future mitigation and preparedness strategies. Recommendations 40 and 53 of the inquiry support this view:

- that new developments and subdivisions in areas of high risk to bushfire be restricted

- that the Sale of Land Act 1962 be amended to require notification of bushfire prone land appear in the vendors statement

Implementing restrictions and informing occupants or future occupants of the area of the risk and history of bushfire will not only support future disaster management but can help inform the current recovery process.

For all disasters where data is produced to support the phases of mitigation, preparedness, response or recovery, the concept of disaster related clearinghouses can be applied. This is a possible solution for sharing all of the critical information required to manage specific disasters. The information made available through these clearinghouses to the larger disaster management community can become an important tool for learning lessons from one event in order to more efficiently manage in a subsequent event. The knowledge transfer from one event to the next and institutional memory is an essential component to all phases of the disaster management cycle (Mills et al 2008b). In general, in the context of the 2009 bushfire disaster, the integration of datasets produced during the bushfires should take place along with the integration of the land administration functions of land tenure management, land value, land use and land development (Fig. 4).

\section{Principle 5: Investigate the use of VGI in recovery activities}

Much of the information used in the recovery phase made use of official datasets. Much less use was made of volunteered geographic information (VGI), data collected from citizens (Fig. 4). VGI has rapidly evolved in recent years due to changes to internet technology, greater availability of data from government sources, the growth of neogeography and an appreciation and understanding of spatial data from the public (Goodchild 2009). Today geographic information is a commonly used web resource, with the majority of users having the capability to contribute information (Scharl and Tochtermann 2007). Hurricane Katrina in 2005 and the California wildfires of 2007 are considered some of the first disasters to benefit from the use of these web based technologies and VGI (Liu and Palen 2010; Zook et al. 2010; Mills et al. 2010; Roche et al. 2011), and recent disasters such as the New Zealand earthquakes, the Tsunami in Japan, and tornados in Alabama reflect a continuation of the use of VGI and web technologies for disaster management purposes (Curtis and Mills 2011). There are good arguments to be made as to why only official data sources should be used, particularly in relation to liability. VGI data brings with it concerns of accuracy and lacks the assurance of quality associated with officially created data (Goodchild and Glennon 2010). However, these emerging data sources are rich in content and often exhibit dynamism not available in government maintained datasets. The role and utility of volunteered data needs to be examined in the context of bushfire disaster recovery. 


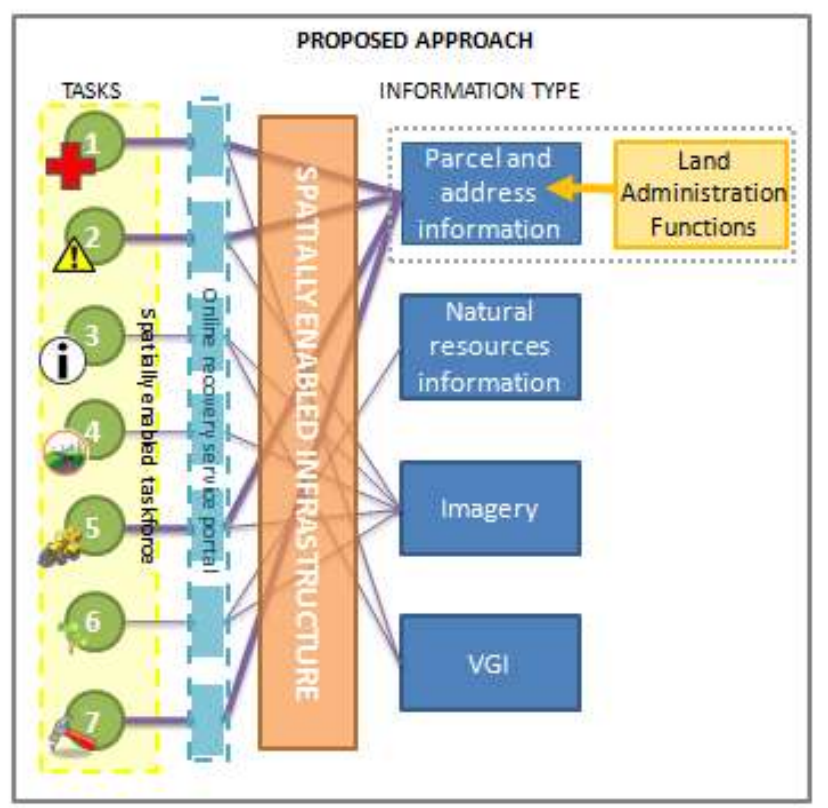

Fig. 4 Proposed approach: spatially enabling bushfire recovery

\section{Conclusion}

In summary, spatial information is an essential resource utilized in disaster management activities including bushfires. Maps and spatial data are critical elements in each of the four phases of disaster management. The use of spatial information to support the phases of mitigation, preparedness and response to bushfires is widely understood, however, it was demonstrated that less attention has been given to the role of spatial information in the recovery.

This paper explored the role that spatial information plays and could play in the recovery phase of a bushfire disaster. The bushfires in Victoria, Australia during February 2009 provided the case materials to analyse the role and potential role further. It was found that spatial information for recovery requires a pre-existing infrastructure consisting of pre defined core datasets, preorganized sharing relationships and standards, and interoperable systems. Moreover spatial capacity must be developed across government agencies dealing with recovery: the pervasiveness of spatial information requires this approach. Additionally, spatially enabled address and parcel information are the key datasets required to support all recovery tasks. More investigation of the potential for integrating bushfire datasets (spread and intensity) and planning regimes is required, additionally; exploration of the role of volunteered geographic information in the recovery phase is required. A comparative analysis between the bushfire event described in this paper and other recent disasters such as Hurricane Katrina (where similar problems with spatial information were identified), as well as a study into the use of spatial information in the medium to long term recovery have been identified as priorities for future work. 


\section{Acknowledgement}

The authors would like to express their gratitude to John Tulloch, Surveyor-General of Victoria, and Duncan Brooks, Manager, Spatial Business Systems, Spatial Information Infrastructure, Department of Sustainability and Environment Victoria; Mark Garvey, Manager, Geographic Information Systems, Country Fire Authority Victoria; Matt Brown, Senior Business Analyst, Emergency Management Branch, and Pam Williams, Director, Bushfire Recovery Services, Department of Human Services Victoria; Nic Moore, Licensed Surveyor, Survey 21; Matt Elgin, Senior Project Manager, Geomatic Technologies Pty Ltd. By sharing their experiences and information about the use of spatial information during the recovery of the Black Saturday bushfires they have provided invaluable insights for this research.

\section{References}

Asante, K. O., Verdin, J. P., Crane, M. P., Tokar, S. A., \& Rowland, J. (2007). Spatial Data Infrastructures in Management of Natural Disasters. In H. Onsrud (Ed.), Research and Theory in Advancing Spatial Data Infrastructure Concepts (pp. 279-293). Redlands, California: ESRI Press.

Atkinson, D., Chladil, M., Janssen, V., \& Lucieer, A. (2010). Implementation of quantitative bushfire risk analysis in a GIS environment. International Journal of Wildland Fire, 19(5), 649-648.

Atkinson, D., Janssen, V., Lucieer, A., \& Chladil, M. A. (2007). Bushfire risk assessment - an integrated approach using GIS. Paper presented at the Spatial Science Institute Biennial International Conference, Hobart, Tasmania, May 2007

Australian Capital Territory. Bushfire Recovery Taskforce (2003). The report of the Bushfire Recovery Taskforce - Australian Capital Territory October 2003 / Bushfire Recovery Taskforce The Report of the Bushfire Recovery Taskforce. Canberra, ACT: Publishing Services for ACT Bushfire Recovery Taskforce, Canberra.

Bonner, M.R., Han, D., Nie, J., Rogerson, P., Vena, J.E. and Freudenheim, J.L. (2003) Positional Accuracy of Geocoded Addresses in Epidemiologic Research. Epidemiology.Vol. 14 No. 4 pp. $408-412$.

Budhathoki, N. R., Bruce, B., \& Nedovic-Budic, Z. (2008). Reconceptualizing the role of the user of spatial data infrastructure. GeoJournal, 72(3-4), 149.

Cameron, P. A., Mitra, B., Fitzgerald, M., Scheinkestel, C. D., Stripp, A., Batey, C., et al. (2009). Black Saturday: the immediate impact of the February 2009 bushfires in Victoria, Australia. The Medical Journal of Australia, 191(1), 11-16.

Cayo, M.R. and Talbot, T.O. (2003) Positional error in automated geocoding of residential addresses. International Journal of Health Geographics. Vol. 2 No. 10

Chandra, A., \& Acosta, J. D. (2010). Disaster Recovery Also Involves Human Recovery. The Journal of the American Medical Association, 304(14), 1608-1609.

Chang, S.E. (2010) Urban disaster recovery: a measurement framework and its application to the 1995 Kobe earthquake. Disasters Vol. 34 No. 2 pp. 303-327.

Chou, Y. H. (1992). Management of wildfires with a geographical information system International Journal of Geographical Information Science, 6(2), 123-140.

Cichocki, E. (2010). Surveying Response to the Victorian Bushfires of February 2009 Paper presented at the FIG Congress 2010: Facing the Challenges - Building the Capacity, Sydney, Australia, April 2010

Crompvoets, J., Bregt, A., Rajabifard, A., \& Williamson, I. (2004). Assessing the worldwide developments of national spatial data clearinghouses. International Journal of Geographical Information Science, 18(7), 665-689.

Curtis, A. and Mills, J. (2011) Spatial video data collection in a post-disaster landscape: The Tuscaloosa Tornado of April 28th 2011. Applied Geography.Vol. 32 pp. 393-400. 
Curtis, A., Mills, J., Blackburn, J. K., \& Pine, J. C. (2006). Hurricane Katrina: GIS Response for a Major Metropolitan Area. Quick Response Report No. 180. Boulder: University of Colorado Natural Hazards Center.

Curtis, A., Mills, J., Kennedy, B., Fotheringham, A., \& McCarthy, T. (2007). Understanding the geography of post-traumatic stress: An academic justification for using a Spatial Video Acquisition System in the response to Hurricane Katrina. Journal of Contingencies and Crisis Management, 15, 186-197.

Davis, I. (2006). Learning from Disaster Recovery: Guidance for Decision Makers, International Recovery Platform (IRP), May 2006.

Denzin, N. K., \& Lincoln, Y. S. (Eds.). (2005). Handbook of qualitative research. Thousand Oaks, California: SAGE Publications.

Ellis, S., Kanowski, P., Whelan, R. (2004). National Enquiry on Bushfire Mitigation and Management. (pp. 43-178): Council of Australian Governments.

Flick, U. (2002). An Introduction to Qualitative Research (2nd edition ed.). London, United Kingdom: SAGE Publications Ltd.

Garnett, J. D., \& Moore, M. (2010). Enhancing Disaster Recovery: Lessons from Exemplary International Disaster Management Practices. Journal of Homeland Security and Emergency Management, 7(1).

Goodchild, M. (2009) NeoGeography and the nature of geographic expertise. Journal of Location Based Service. Vol. 3 No. 2 pp. 82-96.

Goodchild, M.F. and Glennon, J.A. (2010) Crowdsourcing geographic information for disaster response: a research frontier. International Journal of Digital Earth. Vol. 3 No. 3 pp. 231241.

Green, R., Bates, L.K. and Smyth, A. (2007) Impediments to recovery in New Orleans' Upper and Lower Ninth Ward: one year after Hurricane Katrina. Disasters. Vol. 31 No. 4 pp. 311335.

Groot, R., \& McLaughlin, J. (2000). Introduction. In R. Groot, \& J. McLaughlin (Eds.), Geospatial data infrastructure: Concepts, cases, and good practice. Oxford, New York: Oxford University Press.

Hjelmager, J., Moellering, H., Cooper, A., Delgado, T., Rajabifard, A., Rapant, P., et al. (2008). An initial formal model for spatial data infrastructures. International Journal of Geographic Information Science, 22(11-12), 1295-1309.

Hodgkinson, K. (2009). Victorian bushfires. In Legislative Assembly (Ed.): Parliament of New South Wales.

Ingram, J. C., Franco, G., Rumbaitis-del Rio, C., \& Khazai, B. (2006). Post-disaster recovery dilemmas: challenges in balancing short-term and long-term needs for vulnerability reduction Environmental Science \& Policy, 9(7-8), 607-613.

Johnson, R. (2000). GIS Technology for Disasters and Emergency Management. Redlands, California: Environmental Systems Research Institute Inc. .

Liu, S. and Palen, L. (2010) The new cartographers: Crisis map mashups and the emergence of neogeographic practice. Cartography and Geographic Information Science. Vol. 37 No. 1 pp. 69-90.

Mansourian, A., Rajabifard, A., Valadan Zoej, M.J. and Williamson, I.P. (2006). Using SDI and Web-Based System to Facilitate Disaster Management. Computers \& Geosciences, 32, 303-315.

Mansourian, A., Rajabifard, A., Valadan Zoej, M.J., Williamson, I.P. (2004). Facilitating Disaster Management Using SDI. Journal of Geospatial Engineering, 6(1), 1-14.

Masser, I. (2005). GIS Worlds: Creating Spatial Data Infrastructures (First Edition ed.). Redlands, California: ESRI Press.

McLoughlin, D. (1985). A Framework for Integrated Emergency Management. Public Administration Review, 45(Special Issue), 165-172.

Mileti, D. S. (1999). Disasters by design: a reassessment of natural hazards in the United States. Washington, D.C.: Joseph Henry Press.

Mills, J., Curtis, A., Kennedy, B., Kennedy, S.W. and Edwards, J.D. (2010) Geospatial video for field data collection. Applied Geography. Vol. 30 No. 4 pp. 533-547.

Mills, J. W. (2008a). Understanding Disaster: GI Science Contributions in the Ongoing Recovery from Katrina. [Guest Editorial]. Transactions in GIS, 12(1), 1-4.

Mills, J. W., Curtis, A., Pine, J. C., Kennedy, B., Jones, F., Ramani, R., et al. (2008b). The clearinghouse concept: a model for geospatial data centralization and dissemination in a disaster. Disasters, 32(3), 467-479. 
Mohammadi, H., Rajabifard, A., \& Williamson, I. P. (2010). Development of an interoperable tool to facilitate spatial data integration in the context of SDI. International Journal of Geographic Information Science, 24(4), 487-505.

Molina, M., \& Bayarri, S. (2011). A multinational SDI-based system to facilitate disaster risk management in the Andean Community. Computers \& Geosciences, 37, 1501-1510.

Mondschein, L. G. (1994). The role of spatial information systems in environmental emergency management. Journal of the American Society for Information Science and Technology, 45(9), 678-685.

Moodley, D., Terhorst, A. L., Simonis, I., Mcferren, G. A., \& Bergh, F. V. d. (2006). Using the sensor web to detect and monitor the spread of wild fires. Paper presented at the 2 nd International symposium on geo-information for disaster management, Goa, India, September 2006

Petterson, J. (1999). A Review of the Literature and Programs on Local Recovery from Disaster. Boulder, Colorado: Natural Hazards Research and Applications Information Center, Institute of Behavioral Science, University of Colorado.

Rajabifard, A., Feeney, M.E., Williamson, I.P. (2002). Directions for the Future of SDI Development. International Journal of Applied Earth Observation and Geoinformation, 4(1), 11-22.

Rajabifard, A. (Ed.). (2007). Towards a Spatially Enabled Society. Melbourne, Australia: Centre for SDIs and Land Administration.

Rajabifard, A., Crompvoets, J., Kalantari, M., \& Kok, B. (Eds.). (2010). Spatially Enabling Society: Emerging Trends and Critical Assessment. Leuven, Belgium: Leuven University Press.

Rajabifard, A., Mansourian, A., Valadan Zoej, M.J., Williamson, I.P. (2004). Developing Spatial Data Infrastructure to Facilitate Disaster Management. Paper presented at the GEOMATICS'83 Conference, Tehran, Iran,

Rajabifard, A., Williamson, I.P. (2004). Regional SDI Development. Journal of Geospatial Today, 2(5), 86-90.

Ratcliffe, J.H. (2001) On the accuracy of TIGER-type geocoded address data in relation to cadastral and census areal units. International Journal of Geographical Information Science. Vol. 15 No. 5 pp. 473-485.

Roche, S., Propeck-Zimmermann, E. and Mericskay, B. (2011) GeoWeb and crisis management: issues and perspectives of volunteered geographic information. GeoJournal.Vol. 76 No. 6 pp. $1-20$.

Scharl, A. and Tochtermann, K. (2007). The geospatial web: How geobrowsers, social software and the Web 2.0 are shaping the network society. London, Springer.

Scholten, H., Fruijter, S., Dilo, A., \& van Borkulo, E. (2008). Spatial Data Infrastructure for Emergency Response in Netherlands. In Remote Sensing and GIS technologies for monitoring and prediction of disasters (pp. 179-197).

Smith, G. P., \& Wenger, D. (2007). Disaster Recovery: Operationalizing an Existing Agenda. In H. Rodriguez, Quarantelli, E.L., Dynes, R.R. (Ed.), Handbook of Disaster Research (Vol. 1, pp. 234-257). New York: Springer Science.

Victorian Bushfire Reconstruction and Recovery Authority (2009). Rebuilding Together: A Statewide Plan for Bushfire Reconstruction and Recovery. Melbourne: Department of Transport Victoria.

Ward, M.H., Nuckols, J.R., Giglierano, J., Bonner, M.R., Wolter, C., Airola, M., Mix, W., Colt, J.S. and Hartge, P. (2005) Positional Accuracy of Two Methods of Geocoding. Epidemiology.Vol. 16 No. 4 pp. 542-547.

Williamson, I. P., Enemark, S., Wallace, J., \& Rajabifard, A. (2010). Land Administration for Sustainable Development. Redlands, California: ESRI Press.

Yin, R. K. (1993). Applications of Case Study Research (Vol. 34, Applied Social Research Methods Series). Thousand Oaks, California, United States: SAGE Publications Inc. .

Yin, R. K. (2003). Applications of Case Study Research (2nd Edition ed.). Thousand Oaks, California, United States: SAGE Publications.

Zandbergen, P.A. (2008) A comparison of address point, parcel and street geocoding techniques. Computers, Environment and Urban Systems. Vol. 32 pp. 214-232.

Zook, M., Graham, M., Shelton, T. and Gorman, S. (2010) Volunteered Geographic Information and Crowdsourcing Disaster Relief; A Case Study of the Haitian Earthquake. World Medical \& Health Policy. Vol. 2 No. 2 pp. 7-32. 


\section{University Library}

\section{- M M I E E R VA A gateway to Melbourne's research publications}

Minerva Access is the Institutional Repository of The University of Melbourne

Author/s:

Potts, K;Bennett, R;Rajabifard, A

Title:

Spatially enabled bushfire recovery

Date:

2013-02-01

Citation:

Potts, K., Bennett, R. \& Rajabifard, A. (2013). Spatially enabled bushfire recovery.

GEOJOURNAL, 78 (1), pp.151-163. https://doi.org/10.1007/s10708-011-9437-3.

Publication Status:

Published

Persistent Link:

http://hdl.handle.net/11343/32686 